самим языком. «Достичь того, чтобы идти вместе - это то, к чему стремится поэт, как, впрочем, и любой говорящий. Разумеется, он стремится прежде всего идти в ногу с собой, вслушиваться в самого себя, в слово, которое должно подоспеть. Как разговор можно вести лишь с тем, кто еще не знает всего, но прислушивается к тому, что происходит с другим и что исходит от другого, так же дело обстоит и в случае стихотворения и разговора со стихотворением. Существует ошибочная теория, будто сопровождение в понимании, на которое нацелена любая интерпретация, должно быть чем-то вроде конструкции смысла, который, якобы, заключен в стихе. Если бы это было так, нам больше не требовалось бы стихотворение. Скорее, стихи, подобно продолжающемуся разговору, указывают нам в направлении смысла, никогда в принципе не достижимого. Это не реконструкция имеющегося смысла, тем более не редукция к тому, что "замышлял" поэт. Важно во внутреннем разговоре идти в ногу с самим языком - так, как это делают, когда беседуют друг с другом» [10, с. 344].

В художественной литературе мы сталкиваемся один на один с языком, который нас определяет, и от исхода этой встречи зависит наше дальнейшее бытие. Это не значит, что любое произведение должно находить отклик в нашей душе, но так или иначе именно моя языковость, а не идейная близость автору или эстетическая просвещенность, выступает необходимой предпосылкой понимания искусства как особого опыта понимания другого в себе самом.

\section{Список источников}

1. Витгенштейн Л. Логико-философский трактат // Витгенштейн Л. Философские работы. Ч. 1. - М. : Гнозис, 1994. - С. 1-73.
2. Гадамер Г.-Г. Философия и литература // Гадамер Г.-Г. Актуальность прекрасного. - М. : Искусство, 1991. - С. 126146.

3. Гадамер Г.-Г. Философия и поэзия // Гадамер Г.-Г. Актуальность прекрасного. - М. : Искусство, 1991. - С. 116-125.

4. Гадамер Г.-Г. Эстетика и герменевтика // Гадамер Г.-Г. Актуальность прекрасного. - М. : Искусство, 1991. - С. 256265.

5. Гадамер Х.-Г. Истина и метод: основы философской герменевтики / Х.-Г. Гадамер. - М. : Прогресс, 1988. - 704 с.

6. Тракль Г. Песнь отрешенного. Хайдеггер М. Язык поэмы / Г. Тракль ; перев. с нем. Н. Болдырева. - СПб. : Летний Сад, 2014. - $460 \mathrm{c}$.

7. Хайдеггер М. По поводу одного стиха Мерике // Хайдеггер М. Работы и размышления разных лет. - М. : Гнозис, 1993. - С. 243-257.

8. Хайдеггер М. Разъяснения к поэзии Гельдерлина / М. Хайдеггер. - СПб. : Академический проект, 2003. - 317 с.

9. Gadamer H.-G. Gedicht und Gespräch : Essays / H.-G. Gadamer. Frankfurt a. M. : Insel Verlag, 1990. - $184 \mathrm{~S}$.

10. Gadamer H.-G. Gedicht und Gespräch (1988) // Gadamer H.-G. Gesammelte Werke. Bd. 9. Ästhetik und Poetik II : Hermeneutik im Vollzug. - Tübingen: Mohr Siebeck, 1993. - S. 335-346.

11. Gadamer H.-G. Über den Beitrag der Dichtkunst bei der Suche nach der Wahrheit (1971) // Gadamer H.-G. Gesammelte Werke. Bd. 8. Ästhetik und Poetik I : Kunst als Aussage. Tübingen : Mohr Siebeck, 1993. - S. 70-79.

12. Heidegger M. Gesamtausgabe. Bd. 52. Hölderlins Hymne "Andenken“ / M. Heidegger. - Frankfurt a. M. : Vittorio Klostermann, 1992. - $204 \mathrm{~S}$.

13. Heidegger M. Gesamtausgabe. Bd. 53. Hölderlins Hymne "Der Ister" / M. Heidegger. - Frankfurt a. M. : Vittorio Klostermann, 1993. - $210 \mathrm{~S}$.

14. Heidegger M. Gesamtausgabe. Bd. 75. Zu Hölderlin. Griechenlandreisen / M. Heidegger. - Frankfurt a. M. : Vittorio Klostermann, 2000. - $380 \mathrm{~S}$.

\title{
САМУХИН A.X.
}

\section{ЗНАКОВЫЕ ОБРАЗЫ ВИРТУАЛЬНОЙ РЕАЛЬНОСТИ В ПОПУЛЯРНОЙ КУЛЬТУРЕ}

В статье представлен анализ истории появления и развития образов виртуальной реальности в популярной культуре. 0бразы виртуальной реальности рассматриваются в контексте влияния на них философии техники и концепций технического оптимизма и технического пессимизма. Идейные корни образов виртуальности прослеживаются в сфере утопической литературы и футурологии. Основным материалом послужили популярные книги и кинофильмы о виртуальной реальности.

Ключевые слова: виртуальность, виртуальная реальность, компьютерная виртуальная реальность, виртуалистика, популярная культура, массовая культура, матрица, образы виртуальной реальности, киберпанк, социальная сеть. 
0 браз виртуальной реальности в популярной культуре начал активно формироваться в конце XX в., когда в повседневную жизнь людей начали вторгаться компьютерные технологии. Первым этапом в ее распространении стала увязка специализированного по тем временам термина «виртуальность» со словом «реальность». Говоря о популярной (массовой) культуре в контексте настоящей статьи, мы будем иметь в виду культуру быта, развлечений, набор мировоззренческих установок обывателей.

Понятие «виртуальность» было востребовано в философских течениях античности и средневековья. Так, в античности говорили о virtus - активном начале, присущем всему космосу в целом, а также его частям. В средневековье идея виртуальности использовалась для прояснения отношений между божественным и человеческим миром. Затем понятие активно не использовалось долгое время, пока не пригодилось в физике, а также для обозначения объектов виртуальной графики, созданных с помощью компьютерных технологий [7]. Интересно, что сначала технологии виртуальной реальности были закрытыми и применялись в основном военными для создания имитаций боевых действий.

Сегодня проблемой изучения виртуальной реальности занимаются многие зарубежные и отечественные исследователи. Первые часто выступают в роли инженеров и практиков преобразования современных технологий виртуальной реальности. Среди обилия авторов можно выделить Т. О'Рейлли, Ф. Кавацци, Д. Кирпатрика и др. В отечественной научной среде оформился собственный исследовательский подход, получивший название виртуалистика. Его сторонники рассматривают виртуальную реальность с более общих философских позиций и пытаются интегрировать ее в онтологическую картину мира (Н.А. Носов, С.С. Хоружий, А.Ю. Севальников).

Образ виртуальной реальности в популярной культуре начал формироваться под воздействием отношений между техникой и человеком, которые, в свою очередь, были предметом активной дискуссии в сфере гуманитарных наук и философии техники. Компьютер, очевидно, является одной из вершин технического развития человечества, и отношение к нему формируется также в контексте связи человек-машина. Эти отношения можно охарактеризовать как технический оптимизм и технический пессимизм. Первая концепция, зародившаяся в XIX в., связана с появлением первой философии позитивизма, где вера в идеи прогресса и эволюции принимает почти метафизический характер, а техника выступает в роли их главного инструмента. Именно техника становится помощником человека как в работе, так и повседневной жизни, она приносит ему множество благ и облегчает жизнь. Концепция технического пессимизма (антитехницизм) являлась отчасти реакцией на концепцию технического оптимизма. Ее сторонники считают, что вместе с техническим прогрессом происходят процессы дегуманизации и обезличивания человечества [8]. Техника на службе у военных сделала возможным масштабное уничтожение человечества и природы. «Техническая эпоха требует от человека фабрикации продуктов и притом в наибольшем количестве при наименьшей затрате сил. Человек делается орудием производства продуктов. Вещь ставится выше человека» $[1$, с. 8].

В рамках концепции технического оптимизма стал развиваться жанр технократических утопий, где техника рассматривается как панацея от всех проблем человечества, которые в будущем будут решены с помощью научно-технического прогресса. Предвестник жанра Ф. Бэкон, который в 1627 г. написал книгу «Новая Атлантида», в которой предсказал появление многих достижений науки будущего. В XIX-XX вв. вместе с развитием техники этот жанр стал развиваться активнее: на западе его яркими представителями стали знаменитые писателифантасты Г. Уэллс и Р. Бредберри. В своих произведениях они пытались осмыслить влияние технологий будущего на возможную трансформацию социального строя общества [9]. Среди отечественных теоретиков следует выделить идеи русских космистов - В.И. Вернадского и К.Э. Циолковского. Например, Циолковский предлагал проект кардинального преобразования природы в два этапа. На первом этапе планировалось улучшение условий жизнедеятельности на всей планете, в частности орошение пустынь; на втором - предполагалось полностью изменить облик земли: разрядить атмосферу, уничтожить все дикие виды растений и животных, распрямить рельеф земли, а впоследствии проделать то же самое и на других планетах, после уничтожения местной флоры и фауны. Такие идеи стали возможными благодаря определенной мировоззренческой установке: природа мыслилась как «"мертвая мощь мировых сил", и ее целое разделялось на полезное и вредное для человека» [4].

Такие взгляды утопистов плотно смыкаются с жанром футурологии. Футурологию сложно назвать наукой, однако ее появление связано как раз с тем, чтобы перейти от технократических утопий к более обоснованным оценкам будущего, используя помимо художественной фантазии методы экстраполяции, вероятностного анализа и пр. Именно в рамках жанра футурологии стали появляется первые описания еще не актуального, но вполне прогнозируемого образа виртуальной реальности. Одним из первопроходцев в этой области стал С. Лем.

В 1967 г. С. Лем выпустил книгу «Сумма технологий» [5], которая быстро приобрела широкую известность на волне популярности автора как писателя-фантаста. В ней довольно много общего с произведениями жанра технократической утопии и концепцией технического оптимизма. 06 этом свидетельствуют как смелость прогнозов на страницах книги, так и полемический характер многих глав. Сочинение задумывалось как некий итог технологического развития человечества и дальнейший его прогноз, согласно которому развитие техники и технологий позволит решить многие проблемы на Земле, а также преодолеть распространенные философские пред- 
рассудки. Особый интерес для нас представляет раздел «Фантомология». Основной вопрос, который занимает автора, это возможность создания искусственной реальности и подключения к ней человека. Находясь внутри искусственного мира, человек сможет переживать разнообразные ситуации, которые могут быть как предельно похожими на события реального мира, так и оказываться в фантастическом, отличном от нашей реальности измерении. Способы подключения человека к машине варьируются: периферическая фантоматика занимается вопросом подключения через каналы органов чувств, а центральная фантоматика - подключением к машине непосредственно головного мозга человека, в обход каналов тактильных ощущений. Фантомология, таким образом, получает двоякое значение: с одной стороны, она становится наукой о создании фантомного мира иллюзий, а с другой - проектом по инженерии мира параллельной реальности, погружаясь в который субъект с трудом может отличить искусственную реальность от действительности. По мнению С. Лема в будущем будет возможно конструирование таких аппаратов фантомной (виртуальной) реальности, где и вовсе будет невозможно понять, какая реальность настоящая, а какая искусственная.

Это положение нашло свою реализацию во многих популярных произведениях о виртуальной реальности, главным из которых стала знаменитая кинотрилогия фильмов «Матрица» (1999-2003). Тему виртуальной реальности затрагивали в своих произведениях такие известные писатели-фантасты, как А. Кларк и А. Азимов. Они в той или иной степени детальности рассказывали о будущем виртуальной реальности в схожем с «Суммой технологии» ключе, пока в конце 1970-х гг. начал набирать популярность новый антиутопичный жанр фантастики «киберпанк».

В 1984 г. У. Гибсон выпустил книгу «Нейромант» [3], которая по стилю существенно отличалась от остальных произведений того времени. Его появление ознаменовало эпоху расцвета нового жанра в литературе - киберпанк. Киберпанк - это жанр научной фантастики, появившейся в конце 1970-х гг. в среде диссидентов, связанный с осмыслением вторжения в повседневную жизнь высоких технологий. Жанр характеризуется антиутопичным отношением к возможному будущему, которое представляется как эпоха высоких технологий, главным образом компьютерных и кибернетических, доступных мегакорпорациям, в руках которых сосредоточена власть на планете на фоне общего социального упадка и разложения.

Герои романов в жанре киберпанк - это социальные отщепенцы, пытающиеся украсть технологии или ценные артефакты у корпораций, пользуясь нелегальными программами. Жанр можно охарактеризовать как проявление технического пессимизма и реакцию на оптимистические прогнозы на будущее, характерные для научной фантастики того времени. Расцвет жанра пришелся на середину 1980-х гг., когда компьютеры начали входить в жизнь обычных людей. Графические интерфейсы компью- терных программ и игр были еще относительно бедными и не давали богатой почвы для фантазий о виртуальном мире. Именно поэтому при всех попытках создать образ виртуального мира на страницах романа не прослеживается однозначного представления о том, какую именно форму имеет пространство виртуальности с точки зрения как визуального, тактильного наполнения, так и системы внутренних интерфейсов.

Интерфейс компьютерных программ был в основном текстовым или командным, зачастую представленным в виде кода. Для освоения той или иной программы требовалось прочесть не одну книгу, выучить многие команды. Поэтому о специалисте в данной области складывалось мнение, как о человеке, обладающем тайными знаниями, доступными лишь узкому числу посвященных. Именно этот образ и был отчасти воспринят жанром киберпанк. Так, Кейс, герой романа «Нейромант», был сетевым ковбоем-хакером, обладающим по сравнению с другими экстраординарными способностями по взламыванию компьютерных сетей. В произведении сделан акцент на том, что большинство людей, взаимодействующих в сфере киберпространства, обладают особенными навыками, полученными зачастую путем внедрения тех или иных кибернетических устройств в тело, а также после приема стимулирующих химических веществ. Большая часть киберреальности представляет собой трехмерную решетку с вкраплением данных в виде объемных цветных геометрических фигур разной формы. Внутри киберпространства живет Искусственный Интеллект, который пытается обрести свою личность. Лишь группа избранных хакеров может чувствовать себя уверенно внутри такого кибервиртуального мира. Для остальных рядовых пользователей это относительно закрытая территория, где доступен только «симстим» - центр записи и трансляции эмоциональных и визуальных переживаний другим людям с целью получения удовольствия (подобие телерадиовещания). Взаимодействие с пространством виртуальности осуществляется посредством «деки» - набора электродов, надевающихся на голову. Роман У. Гибсона иллюстрирует один из главных принципов жанра киберпанк High tech, low life, что означает низкий уровень жизни населения на фоне стремительно развивающихся высоких технологий, недоступных массам.

С выходом «Нейроманта» образ виртуальной реальности стал набирать популярность и лег в основу сюжета многих других произведений этого стиля, например «Интерфейсом об тейбл» Б. Стерлинга, «Вирт» Дж. Нуна, «Анклавы» В. Панова и др. Литературный жанр, в свою очередь, дал много идей для кинофильмов. По мере популяризации киберпанка начал уменьшаться его уровень противопоставления массовой культуре. Виртуальная реальность стала входить в сферу кино, постепенно снижался градус социального противостояния, а жанр начал вырождаться в так называемый пост-киберпанк, который стал некоторым приспособлением и популяризацией киберпанка для широкой аудитории. 
Первым кинофильмом о виртуальной реальности с применением технологий компьютерной графики стал фильм «Трон» (1982) режиссера С. Лисбергера. Герой фильма Флинн попадает в пространство виртуальности, будучи оцифрованным, и начинает бороться против Искусственного Интеллекта, который пытается подчинить себе все другие программы и для этого пытается найти программу Трон. Программы в виртуальной реальности имеют человеческий облик. Их образ существования антропоморфен: в фильме мы видим, что у программ есть эмоции, они участвуют в интригах. Пространство виртуальной реальности представлено как огромный светящейся корабль, движущийся к центру светящегося города, по которому перемещаются, пешком или бегом, человекообразные программы. Сюжет картины незамысловат: герои находятся вдали от внутренних конфликтов и философских дилемм, пытаясь освободиться от власти антропоморфного Искусственного Интеллекта.

Фильм «Газонокосильщик» (1992) стал одной из первых попыток кинематографа в экранизации сюжета с элементами киберпанка и анализом тематики виртуальности в философском ключе. Согласно сюжету, умственно отсталый газонокосильщик Джоб под воздействием химических стимуляторов и занятий в комнате виртуальной реальности осуществляет скачок в развитии, приобретая сверхспособности в реальном мире, осуществляет загрузку своего сознания в киберпространство с целью получения контроля над миром. Виртуальная реальность представлена как многоуровневая структура, в которой можно выделить уровень локальных машин, главного сервера лаборатории виртуальной реальности и всемирной сети, куда проник Джоб, после того как загрузил свое сознание в сеть. Виртуальная реальность в фильме - программируемое трехмерное пространство, в него попадают люди путем подключения виртуального костюма и трехмерных очков к серверу виртуальной реальности. Будучи подключенным, человек получает виртуальное тело, визуально схожее с человеческим, он может манипулировать виртуальными вещами, а также проходить виртуальное обучение. Начиная с этой киноработы, источником образа виртуальной реальности все чаще становятся реальные компьютерные технологии, а не домыслы писателейфантастов. Фильм отражает концепцию технического пессимизма, когда необдуманное использование новых технологий может привести к трагедиям как на локальном уровне, так и в более широких масштабах.

В целом, в 1990-х гг. образ виртуальной реальности прочно вошел в кинематограф в качестве тренда научно-фантастических фильмов. Идейные линии отчасти черпались из литературы, в том числе жанра киберпанк, а также заимствовались из указанных кинокартин. Фильмы отличались относительно простым сюжетом и ориентацией на массового зрителя. Философско-культурологическая проблематика практически отсутствовала, однако стала использоваться тематика компьютерных игр, которые в то время активно развивались и распространялись.
Примерами таких картин могут служить: «Электронные бойцы» (1995), «Нирвана» (1997), «Экзистенция» (1999). Кинофильм «Тринадцатый этаж» (1999) - это зарисовка на тему многоуровневой вселенной, где один мир - это ограниченная компьютерная модель другого, несуществующего мира, находящаяся внутри мира первого порядка, который, в свою очередь, находится внутри еще более глобального мира. В таком мире виртуально воссоздан город прошлого и люди, являющиеся компьютерными ботами. Детективный сюжет и концовка намекают, что неизвестно, какой мир является основным. В целом картина отражает пессимистическую идею о том, что и наш мир может оказаться подделкой, которую практически невозможно отличить от оригинала. Особенно эффектно эта гипотеза была показана в картине «Матрица».

Трилогия фильмов «Матрица» (1999-2003) стала своеобразным художественным и философским итогом на пути осмысления и экранизации образа виртуальной реальности в популярной культуре. Главная философская подоплека картины - это противостояние искусственного и естественного миров, где первый вышел из-под контроля, обретя разумность, и подчинил себе все живое, в том числе человека, поместив его в матрицу - программу тотальной симуляции реальности. Помимо отсылок к философии техники, фильм использует идеологемы философии нового времени, постмодернизма, а также восточной философии и христианства; очевидно влияние целого пласта фантастической литературы, включая киберпанк. Виртуальная реальность в «Матрице» предстает в образе проекта тотальной симуляции бытия с помощью совершенной компьютерной модели, к которой подключены все люди на планете путем соединения их мозга непосредственно с компьютером (центральная фантоматика Лема). Внутри матрицы находятся все города и страны, а люди живут привычной жизнью, не подозревая о том, что находятся лишь в симуляции. Иногда матрица дает сбои, и некоторые начинают подозревать, что с миром что-то не так. К матрице подключаются повстанцы, которые борются против Искусственного Интеллекта - создателя матрицы, они могут подстраивать код под себя и обретать в мире матрицы сверхспособности. С помощью других виртуальных программ приобретаются любые навыки или знание мгновенно (необходимые данные загружаются непосредственно в мозг). Внутри матрицы также живут программы, которые имеют человеческий облик и преследуют свои цели, руководствуясь, однако, антропоморфными мотивами. Герой фильма Нео, обретя сверхспособности, преобразует матрицу и, жертвуя собой, достигает перемирия между миром машин и людей.

Кинофильм стал классикой своего жанра, после него не предпринимались попытки создать нечто более глобальное в том же ключе. Отметим, что «Матрица» ярко иллюстрирует идеи технического пессимизма, когда буквально все технологии, созданные человеком, включая виртуальную реальность, обратились, в конечном счете, против него. Этой кинокартиной подведен некоторый 
итог апокалипсическим идеям захвата мира ожившими компьютерами, началось использование других образов виртуальной реальности, которые были навеяны уже не фантастической и философской литературой, а реальным положением дел в сфере развития технологий виртуальной реальности. Вместе с широким распространением Интернета, получило популярность представление о виртуальной реальности как о сфере развлечения, где люди проводят время, общаясь друг с другом или играя в видеоигры по сети. Эти представления, набирая все большую известность, шли вразрез с пессимистическими прогнозами разнообразных фильмов и книг о трагическом завершении эры компьютерных технологий.

Коммуникации в Интернете, с помощью чатов, форумов и мессенджеров повсеместно распространившись в конце 1990-х гг., дали почву для литературы разного толка. Так, в 2001 г. вышла книга Я.Л. Вишневского «0диночество в сети» [2]. В ней рассказывается о романе двух людей, чье знакомство началось в Интернете и продолжилось в реальном мире. Образ виртуальной реальности в романе - это референция ее реальной части в современной культуре: поле для общения и новых знакомств. «Шлем ужаса» В. Пелевина (2005) [6] - это переложение мифа о Тесее и Минотавре на современный язык. Герои романа, оказавшись в изолированных комнатах, могут общаться между собой только посредством чата. Виртуальная реальность для них становится единственным доступным коммуникативным полем.

Компьютерные игры, получившие большое распространение примерно в то же время, оказали большое влияние на молодых авторов. Развитие игр пошло таким путем, что в начале 2000-х гг. появились онлайн-игры через Интернет, когда на одном игровом поле могут встречаться тысячи игроков. Этот тип игр получил название MMORPG (многопользовательская ролевая игра). Во вселенной такой игры обычно разворачиваются виртуальные баталии между игроками, с переходами на разные уровни и приобретением специальных способностей. Эту игровую механику взяли за основу авторы так называемого поджанра литературной фантастики ЛитРПГ [10]. Произведения этого жанра рассказывают языком геймеров о приключениях тех или иных героев с описанием характерной механики многопользовательской игры. ЛитРПГ получил большую популярность в среде поклонников онлайн-игр, однако затем стал терять свою массовость. Сами видеоигры лишь отчасти являются элементом массовой культуры: в среде взрослых людей чаще встречаются лишь любители. Также и жанр ЛитРПГ ориентирован, скорее, на любителей видеоигр, хотя и пользуется относительно большим успехом. Примерами произведений могут служить «Господство клана Неспящих» Р. Михайлова, «Играть, чтобы жить» Д. Руса.

Огромное влияние на образ виртуальной реальности оказало появление и широкое распространение социальных сетей. Именно социальные сети и их ориентированность на реальный мир позволили создать положительный образ виртуальной реальности, отражающий подход технического оптимизма: компьютер - это средство коммуникации, а не редкая и опасная вещь, используемая знатоками и мегакорпорациями (лейтмотив киберпанка). Такой образ виртуальной реальности, по сути, упразднил в популярной культуре предыдущие образы, созданные фантастикой и киберпанком. Виртуальная реальность отныне это не «матрица» с ее поддельным миром во главе с искусственным интеллектом и программами, стремящимися к власти, а дружественная среда для общения, обмена информацией и эмоциями, доступная всем и каждому.

Фильм «Социальная сеть» рассказывает об истории создания и развития самой популярной сети «Facebook». М. Цукерберг, герой фильма и прообраз реального создателя социальной сети, не создал ничего нового. 0н лишь обобщил потребность в онлайн-коммуникациях, присущих, в первую очередь, молодым людям, и на базе доступных веб-технологий создал первую популярную во всем мире социальную сеть. Главным фактором ее роста и известности стало использование реальных имен людей. Коммуникации переориентировались на обмен информацией о реальной жизни, покидая поле вымышленного общения между анонимными пользователями, скрывающимися под псевдонимами. Таким образом, сейчас образ виртуальной реальности в популярной культуре - это образ открытой социальной сети, когда практически все пользователи реальны и находятся в постоянном онлайнвзаимодействии, обмениваясь разной информацией. Этот образ отвечает концепции технического оптимизма или, скорее, технического реализма, когда новые технологии служат людям во всех сферах, а прогнозы об их тотальности в будущем отходят на второй план.

Итак, на протяжении своего существования образ виртуальной реальности сильно менялся. Сначала он формировался под воздействием фантастической литературь и научных догадок футурологии. По мере развития реальных технологий виртуального пространства источником вдохновения для создания художественных образов стали именно они. Если 15-20 лет назад образ компьютерного апокалипсиса был весьма популярен, то сейчас виртуальная реальность представляется как дружественная среда для общения и ведения бизнеса. Об этом свидетельствуют примеры унификации работы многих компаний, с помощью программных продуктов обменивающихся данными онлайн. В таких сферах, как внешнеэкономическая деятельность, туризм, торговля и многих других, сейчас недопустимо отсутствие интернет-доступа. Еще более впечатляющими выглядят примеры интернет-маркетинга через социальные сети. Практически любая современная компания имеет помимо сайта странички в социальных сетях, где ведет рекламные компании, а также осуществляет общение со своими клиентами.

Однако старые образцы восприятия виртуальной реальности, как чего-то потустороннего, хакерского (киберпанк), тотального (матрица), не ушли в прошлое, а 
продолжают поддерживаться, пользуясь при этом гораздо меньшей популярностью и заняв свою нишу в культуре.

\section{Список источников}

1. Бердяев Н.А. Человек и машина (проблема социологии и метафизики техники) // Путь. - 1933. - № 38. - С. 3-37.

2. Вишневский Я.Л. Одиночество в сети / Я.Л. Вишневский ; [пер. с пол. Л. Цывьяна]. - СПб. : Азбука-классика, 2005. - 442 c.

3. Гибсон У. Нейромант / У. Гибсон ; пер. с англ. В. Ахметьевой [и др.]. -СПб. : Азбука, 2015. - 476 с.

4. Гурленова Л.В. Идеи технократической утопии К. Циолковского в литературе 1920-1930-х годов [Электронный ресурс] // Международный журнал экспериментального образования. - 2009. — № 3. — URL: http://www.rae.ru/ meo/?section=content\&op=show_article\&article_id=38 (дата обращения: 15.11.2015).

5. Лем С. Сумма технологии / С. Лем ; пер. с пол. Ф. Широков. - М. : АСТ ; СПб. : Terra Fantastica, 2004. - 668 с.
6. Пелевин В.О. Шлем ужаса / В. Пелевин. - М. : Эксмо, 2011. - $214 \mathrm{c}$.

7. Самухин А.Х. Три подхода к трактовке виртуальности [Электронный ресурс] // Исторические, философские, политические и юридические науки, культурология и искусствоведение : Вопросы теории и практики. - 2014. № 3. - 4. 1. - C. 141-144. — URL: http://www.gramota. net/materials/3/2014/3-1/37.html (дата обращения: 15.11.2015).

8. Современные философские проблемы естественных, технических и социально-гуманитарных наук : учебник для аспирантов и соискателей ученой степени кандидата наук / под общ. ред. В.В. Миронова. - М. : Гардарики, 2006. — 639 с.

9. Утопия и антиутопия в мировой художественной литературе : [материалы для выставки] [Электронный ресурс] / подгот. С.С. Жигалкина // Информационный портал научной библиотеки им. Е.И. Овсянкина. — URL: http://library. narfu.ru/rus/TRResources/VirtualExhibitions/Pages/utopiay. aspx (дата обращения: 15.10.2015).

10. LitRPG [Электронный ресурc]. — URL: http://litrpg.ru/ (дата обращения: 15.11.2015).

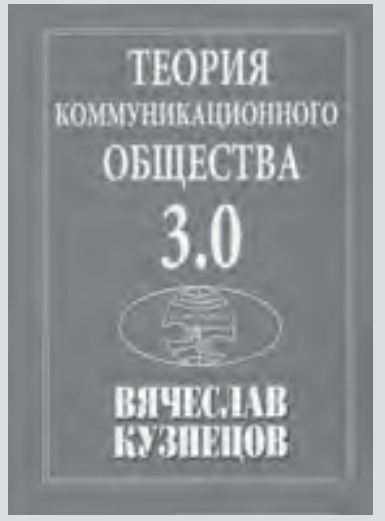

Кузнецов В.Н. Теория Коммуникационного Общества 3.0: социологический гуманистический аспект / В.Н. Кузнецов. - М. : Книга и бизнес, 2015. - 488 с. - ISBN 978-5-212-01315-4.

В научной монографии представлены итоги социологического исследования становления и оформления Позитивной Теории гуманистического феномена «коммуникационное общество XXI века». Генезис нового глобального института рассмотрен в сопоставлении и взаимосвязи с формированием и функционированием информационного общества в XX и XXI веках. Предметная, гуманистическая оригинальность феномена «коммуникационное общество 3.0» определяет содержание концепта «коммуникационное»: это ситуация, состояние, процесс и результат личного и общего в осуществлении деятельности по созданию и учреждению достойного смысла жизни, его означиванию и пониманию; по формированию свойства свободы и ответственности, прав и обязанностей, доверия, справедливости, совести и чести в многообразии участия в личном качестве по производству и движению событий и сообщений.

Движущим, объективным локальным, региональным и глобальным фактором, который способствовал учреждению самостоятельного нового позитивного гуманистического института, стала глобальная структурная гуманитарная революция XXI века как условие и необходимость эволюционного перехода от общества 2.0 к обществу 3.0; от Культуры Мира 2.0 к Культуре Миролюбивого Мира 3.0. Это процесс и результат изменений содержания и структуры мироустройства XXI века, всего миропорядка, оснований мировоззрения и гуманизма под воздействием слабых связей, слабых влияний, слабых рисков; начало доминирования во всех сферах жизнеобеспечения, во всех видах позитивного эволюционного взаимодействия компромиссного, партнёрского, культурного, гуманитарного. Средой и контекстом становления, функционирования, эволюционного развития, источником энергетики и динамики уже оформилось видение мира, мировоззрение, философия истории, в которых Мир XXI в. трактуется, воспринимается как Культура - Сеть, как Глобальный Компромисс, как Глобальная Игра с итогом не равным нулю (尹0), как Гуманистический Гуманизм, как Культура Коммуникации. 